\title{
Оруэлл: честное слово в эпоху идеологических конфликтов
}

\author{
М.Ф. ЧЕРНЫШ*
}

\begin{abstract}
*Михаил Федорович Черныш - член-корреспондент РАН, доктор социологических наук, заместитель директора, Институт социологии РАН. Адрес: 117218, Москва, ул. Кржижановского, д. 24/35, к. 5. E-mail: che@isras.ru

Цитирование: Черныш М.Ф. (2021) Оруэлл: честное слово в эпоху идеологических конфликтов // Мир России. Т. 30. № 1. С. 163-172. DOI: 10.17323/1811-038X-2021-30-1-163-172
\end{abstract}

В России английского писателя Джорджа Оруэлла знают прежде всего как острого критика советского тоталитарного режима, автора романа «1984» и сатирической комедии «Скотный двор». Однако литературное наследие Дж. Оруэлла, его политическое послание не исчерпывается этими двумя произведениями. Джордж Оруэлл придерживался соичалистических убеждений, выступал как противник колониальной политики Великобритании, сражался против фашизма в Испании, где получил тяжелое ранение. Его антитоталитарная позиция не имела конкретной географической адресации, тоталитарные практики он рассматривал как развитие отношений неравенства, эволюцию практик господства, которые рождает капиталистическое общество. В любых обстоятельствах Дж. Оруэлл стремился сохранять за собой право иметь независимую точку зрения на происходящее, поддержать позищию справедливости.

Ключевые слова: Оруэлл, капитализм, колониализм, неравенство, тоталитаризм, господство, справедливость

Гегелевское «история повторяется как фарс», продублированное К. Марксом в работе «Восемнадцатое брюмера Луи Бонапарта», стало не только популярным клише, но и новым способом осмысления истории, которая повторяется - «ибо возвращаются реки к истокам, из которых начали течь», - но ее повтор никогда не буквален, никогда не точен до последней буквы. История, в тех случаях, когда она обнаруживает похожесть нового на старое, пронизана иронией, консервативна и мелочна. Претензии на римское величие, оправданные масштабами великих 
революций, выглядят неубедительно в тех случаях, когда выдвигаются в иную эпоху и служат не идеям радикального переустройства мира, а укороченной надежде на сохранение статус-кво, на удержание в слабеющих руках власти и прежних привилегий. Парадоксально, но Джордж Оруэлл во всех поворотах и повторах истории оказывался фигурой, избежавшей девальвации, его послание нисколько не утратило своего значения и звучит сейчас как грозное предупреждение миру сегодняшнему и будущему. В самом главном, последнем его произведении «1984» задан временной рубеж, по отношению к которому современное общество будет сверять свое состояние: где мы сейчас, смогли ли мы поставить пределы властям, подбирающимся, - во благо, разумеется, - к частной жизни гражданина, желающих контролировать каждый его шаг, каждый вдох и каждый выдох? Где истинные истоки натуженной любви к власти, более похожей на стокгольмский синдром, чем на признание заслуг, по большей части отсутствующих? Советская пропаганда испытывала по поводу этой даты явный дискомфорт, некоторые ее идеологи настаивали (и, возможно, не без некоторых оснований), что Дж. Оруэлл, разоблачавший железные клетки реального социализма, метил не столько в Советы, сколько в страну, гражданином которой он на тот момент являлся - в Великобританию. Чудовищный режим, который он представил в «1984», утверждала советская пропаганда, нисколько не похож на СССР в расслабленную эпоху застоя, он - не более чем пророческое видение тех состояний, в которые могут войти империалистические общества, если тенденции контроля над умами, которые в них возобладали, получат дальнейшее развитие. При этом сама книга в Советском Союзе предсказуемо не издавалась, дабы читатель не смог сравнить прочитанное с тем, что наблюдал вокруг себя, и тем, что знал, хотя и с купюрами, об относительно недавней отечественной истории.

Не прошло и двух лет после 1984 г., как в Советском Союзе начались серьезные изменения, открывшие Дж. Оруэлла широкому читателю. В эпоху перестройки Дж. Оруэлл вышел из тени, чтобы рассказать о собственных прозрениях, о знании, которое он обрел в эпоху тоталитарных идеологий и больших войн, о том, как междоусобица, рожденная проекцией тоталитарной власти, ослабляла силы сопротивления фашизму сначала на периферии, а потом и в центре европейского континента. В эпоху перестройки и несколько позже он смотрелся едва ли не сторонником радикальных экономических реформ, едва ли не адептом дикого капитализма, открывшего дорогу разделения общества на бедных и богатых, на эгоистичную элиту и неимущую массу. Надо ли говорить, что мобилизация Дж. Оруэлла в защиту периферийного капитализма со всеми его эксцессами не имеет ничего общего с его действительной позицией, его настоящими взглядами, которые он пронес через все нелегкие испытания и которые сохранил и в последние свои дни. Оруэлл перевернулся бы в гробу, если бы узнал, что его славят представители общества Джона Берча, организация крайне правых в США: «Энтузиазм, с котором общество Джона Берча приняла Оруэлла, привел бы его в ярость, хотя для многих из его левых оппонентов это было бы доказательством его измены» [Ingle 2006, p. 3]. От себя добавим, что он возмутился бы, узнав, что его благоговейно упоминает в своих идейных манифестах Норман Подгорец, отец неоконсерватизма: если бы Дж. Оруэлл был жив, он был бы в наших рядах, в рядах неоконов [Podhoretz 1983]. Нет, Н. Подгорец явно тасует карты к своей выгоде. Джордж Оруэлл с гневом отверг бы любые притязания неоконов, неолибов 
и прочих «нео» на свое наследство, имя и идеи. Он отверг бы эти притязания потому, что всю жизнь он защищал тех самых пролов - низшие классы, рабочих и работниц, бирманских бедняков, которым британское колониальное господство не оставило надежды, идеалистов, ставивших дело освобождения выше собственных интересов и даже жизни. Да он и сам был таким - социалистом-демократом до мозга костей, не давшим ни единого повода считать его отступником.

О своем социальном статусе он говорил с иронией: «Низший слой высшего слоя среднего класса». Джордж Оруэлл окончил Итон, школу, из стен которой, как говорят, вышло большинство английских премьер-министров, само существование которой есть ярчайшее свидетельство незыблемости социального порядка в англосаксонском мире. В отличие от одноклассников, Дж. Оруэлл не смог продолжить обучение в университете, доходов семьи не хватило на то, чтобы оплатить учебный курс. По совету влиятельных родственников он устроился в имперскую полицию в Бирме, одной из британских колоний. Режиму власти, который он открыл для себя в Бирме, он дал предельно короткую характеристику - «колониальный рэкет». Свои бирманские воспоминания он обобщил в романе «Дни в Бирме», который не получил широкого признания при его жизни, а лишь постепенно, спустя многие годы, стал цениться как одно из тонких, ироничных наблюдений за тем, как и чем жила периферия британской империи в период между двумя великими войнами [Оруэлл 2012]. Он констатировал, что народ-господин точно также разлагается под бременем отстроенной системы колониальных отношений, как и народ, находящийся у него в подчинении. Его власть, сами отношения господства и подчинения способны рождать взаимную ненависть, которая, в свою очередь, отнимает у каждого из вовлеченных в эти отношения сообществ саму возможность развиваться. Собственные размышления о том, что такое колониализм, Дж. Оруэлл вложил в уста Флори, главного героя романа: «В центре всех размышлений, всех досадных впечатлений заполыхала ненависть к отравившему, кажется, сам здешний воздух империализму. Мозг работал и работал (мозгам ведь не прикажешь “стоп" - известная драма недоучек, созревающих поздно, когда обидную судьбу не переделать), и Флори постигал правду насчет родимой матушки Империи. Британская Индия являлась тиранией, несомненно благожелательной, однако все же тиранией, созданной ради грабежа. И ко всем белым на Востоке, всем этим сахибам, среди которых ему выпало существовать, Флори начал испытывать злобное отвращение» [Оруэлл 2012, с. 36].

По возвращении в Европу Дж. Оруэлл продолжил исследования неравенства в разных его формах, совершал все более длительные вылазки в бедные кварталы Лондона. В бедняках он находил таких же людей, как он сам, людей, в которых живут лучшие человеческие качества - желание свободы и стремление к достоинству. Он все более убеждался, что в обществе будущего не должно быть неравенства в его крайних, патологических формах, но социализм таким, каким он его видел, явным образом расходился с идеями предельного огосударствления, которые стали мейнстримом в среде социалистов той эпохи. В романе «Дорога на Уиган-Пирс» Дж. Оруэлл первую часть посвящает рабочим-шахтерам, низведенным до уровня выживания во времена Великой депрессии, а вторую - их якобы защитникамсоциалистам, погрязшим во фракционных склоках, личных амбициях и дешевой рисовке [Оруэлл 2018]. Джордж Оруэлл сознательно дистанцируется от роевой логики социалистического движения, выделяя подходящее для себя место вдали 
от любых мобилизационных построений. Его биографы скажут потом, что он в самом начале своей политической биографии стремился к позиции аутсайдера, предпочитая ее любой другой даже в ущерб известности и доходам.

Автор романа «1984» в тот момент уже настолько разошелся с большинством левых партий, что издательства левой ориентации отказывались печатать даже самые значительные его произведения. Развод с коммунистами и сочувствующими им левыми партиями не сделал Дж. Оруэлла адептом капитализма, любимцем английских правых, которые в салонах, в приватных беседах не стеснялись сочувствовать Адольфу Гитлеру, рассчитывали на то, что он уж точно найдет возможность поставить заслоны на пути коммунизма.

Джордж Оруэлл продолжал писать на тему, которая ему близка, - о системе неравенства, на сохранение которого были направлены усилия правых партий. В 1927 г. он переехал в Париж, жил в кварталах для бедных, этнографически, через собственный опыт познал, как живут низшие классы. На все, что с ним происходило, он смотрел как журналист и наблюдатель, занявший выгодную высоту. Опыт жизни в среде бедняков позволил ему утвердиться в мысли, которая настойчиво посещала его в бирманский период: беды человеческие происходят из неискоренимых пороков капиталистической системы, из культивируемого ею презрения к низшим классам. В 1929 г. он попал в больницу для бедных в 5-м округе Парижа с подозрением на воспаление легких. Болезни легких, преследовавшие его с детства, догонят его два десятилетия спустя, в тот период жизни, когда к нему придет всемирная слава. Наблюдения за медициной он обобщил в короткой, но жесткой новелле под названием «Как умирают бедные» [Оруэлл 2018]. Если богатым и сильным мира сего определены наилучшие условия для выздоровления, то с бедными в клиниках не церемонятся: во французской клинике Дж. Оруэлла лечили исключительно банками и горчичниками, никакие средства или медицинские препараты не применялись. Медицина бессердечна, равнодушна, примитивна, если ее пациенты не имеют толстого кошелька или высокого статуса. Так устроена жизнь в капиталистическом обществе у тех, кто находятся в придонных слоях, она как в гоббсовом первичном состоянии - solitary, poor, nasty, brutish and short.

Джордж Оруэлл понимал, возможно, даже лучше, чем многие его современники, что из искры фашизма, которая зажглась в Испании, возгорится большой пожар, в которой все, что ему дорого, все те ценности, которые он считал основополагающими, окажутся под угрозой. У него не было сомнений: нужно быть в Испании, там идет сражение, исходом которого будет новый расклад сил в Европе. Оруэлл пытался присоединиться к добровольцам, которых посылали в Испанию коммунисты, но они не захотели видеть в своих рядах слишком независимого и наблюдательного человека. Ему помогли представители Международной лейбористской партии. То, что он увидел в Барселоне, находившейся под контролем анархистов, вселило в него надежду: рабочие держали власть в своих руки и управляли городом в интересах его граждан. Однако плохо вооруженные анархисты не смогли сражаться на два фронта: с фалангистами, с одной стороны, и коммунистами, с другой. Коммунисты считали анархистов не союзниками, а врагами: в воюющей Испании они устраивали публичные процессы над анархистами и троцкистами, совсем как в большевистской России. Иногда кажется, что остервенение, с которым они выкорчевывали из левого движения возможных конкурентов, превосходило их ненависть к фашистам. Джордж Оруэлл провел в Испании 115 дней, он не покинул 
Испанию, когда анархистам пришлось сдать позиции, вступил в интербригады, в которых активную роль играли представители Коминтерна, где сам едва не стал фигурантом публичного процесса из-за неосторожности членства в Объединенной рабочей марксистской партии (POUM) - маленькой партии, которую связывали с именем Троцкого и его идеями. От нависшей угрозы его «спасла» пуля фалангистского снайпера, угодившая в горло. Дж. Оруэлл чудом выжил, выкарабкался, прошел вместе с женой Айлин через все кордоны и вернулся в Англию. Здесь он по горячим следам написал книгу «Памяти Каталонии», которую, несмотря на актуальность тематики, отказались принимать левые издательства [Оруэлл 2003]. В левом движении, да и английском обществе в целом, считалось, что в сложившихся обстоятельствах не следует делать предметом обсуждения внутренние противоречия, не стоит обсуждать борьбу левых с фашизмом. Каким бы ни был сталинский СССР, но он был единственной силой (и это признавал сам Дж. Оруэлл), способной вести на равных борьбу с более страшным и опасным врагом, каковым был на тот момент немецкий фашизм. Но был ли сталинизм реальной альтернативой фашизму? По мнению Дж. Оруэлла, меньшим злом несомненно, но реальной демократической альтернативой - нет.

Достаточно ли того, что мы знаем об Дж. Оруэлле, чтобы назвать его «иудушкой» левого движения, готового нанести социалистам удар в спину именно тогда, когда они более всего нуждались в поддержке? И был ли он точен в описании советского общества, строящего, сражающегося, побеждающего? Для того чтобы ответить на эти вопросы, надо точно знать, что Дж. Оруэлл старался представить именно советское общество в тех карикатурных образах прошлого и будущего, какими стали «Скотный двор» и «1984». Казалось бы, это так. В пользу этого говорят давние, со времен Испании, счеты Дж. Оруэлла со сталинистами и его принципиальное неприятие коммунистического движения. Однако надо иметь в виду, что эти два произведения вышли в разное время: «Скотный двор» - накануне Второй мировой, когда Советский Союз находился с Великобританией в союзнических отношениях, а левые связывали с его стойкостью, его победами надежду на сокрушение фашизма [Оруэлл 2017]. В этих обстоятельствах и левые, и интеллектуалы, близкие к правительству, предпочитали закрывать глаза на репрессивный характер советского режима, приглушали любую его критику. Именно поэтому «Скотный двор» встретили недружелюбно, и ведущие издательства отказались печатать его, и хотя в конце концов издателя найти удалось, но тиражи были невелики. Роман «1984» вышел тогда, когда фашизм был разгромлен, союзнические отношения распались, политический климат изменился, и в новой ситуации советская Россия вернула себе статус немезиса коллективного Запада и главной угрозы его влиянию [Оруэлл 2016]. Книга разошлась миллионными экземплярами: правые и левые антисталинисты увидели в ней то, что хотели видеть - жесткую обструкцию идеям и практикам сталинизма в литературной форме, доступной массовому читателю. В конце концов она оказалась на одной полке обличительной литературы вместе с написанным много позже «Доктором Живаго» Бориса Пастернака и потрясшим основы реального социализма романом «Архипелаг ГУЛАГ» Александра Солженицына. В пылу идеологической борьбы прошло незамеченным то, что события «1984» разворачиваются не в советской России, а Великобритании, не современной, а придуманной, возможной в том случае, когда мир поделится на тоталитарные империи, находящиеся друг с другом в постоянной конфронтации. Имперская 
идея не была новой: ранее с ней выступил близкий к Шарлю де Голлю философ Александр Кожев, считавший, что история привела к возникновению совершенной организации - национального государства, которое в конечном итоге самой логикой истории обречено войти в одно из крупных межгосударственных образований, своего рода империй [Nickols 2007].

В параллельном мире «1984» таких империй всего три: Океания, Евразия и Остазия. О том, что происходит во второй и третьей, нам практически ничего не известно, мы можем наблюдать лишь то, что происходит в первой из них. В ней царит ангсоц - социализм по-английски, продукт эволюции британского империализма и британской культуры. Культурный контекст выдает себя сразу в именах главных героев. Это - не Иваны да Марьи, а Уинстон Смит, Джулия, О’Брайен. В Океании установился репрессивный тоталитарный режим, унифицированный по многим характеристикам с другими, известными Дж. Оруэллу, режимами - советским и германским. Но Океания - это не Советский Союз и не Россия, о чем исчерпывающе сказано в статье Р.Р. Вахитова ${ }^{1}$. Идея Дж. Оруэлла заключается в том, чтобы показать, что тоталитаризм, в какой бы стране, в каких бы обстоятельствах он ни возник, неизменно обладает рядом типичных характеристик. О том, в чем суть подобных режимов и почему они так похожи, Дж. Оруэлл рассказал в одном из своих эссе:

«Тоталитаризм посягнул на свободу мысли так, как никогда прежде не могли и вообразить. Важно отдавать себе отчет в том, что его контроль над мыслью преследует цели не только запретительные, но и конструктивные. Не просто возбраняется выражать - даже допускать - определенные мысли, но диктуется, что именно надлежит думать; создается идеология, которая должна быть принята личностью, норовят управлять ее эмоциями и навязывать ей образ поведения. Она изолируется, насколько возможно, от внешнего мира, чтобы замкнуть ее в искусственной среде, лишив возможности сопоставлений. Тоталитарное государство обязательно старается контролировать мысли и чувства своих подданных по меньшей мере столь же действенно, как контролирует их поступки» [Оруэлл 2015, с. 132]. Тоталитаризм, полагает Дж. Оруэлл, невозможно свести к простому диктату, история которого насчитывает тысячи лет, он вырастает из экспансии государства и тех новых технологий контроля над умами, которое оно ставит себе на службу.

Неверно думать, что идеология - это фиксированная сумма идей; в новой трактовке идеология - это зыбкое семантическое поле, с легкостью меняющее свой контур и содержание. Свобода мысли индивида состоит не только в том, чтобы иметь право размышлять о чем угодно и делиться этим с окружающими. Она еще и в том, чтобы избежать определенности и предопределенности, иметь право и возможности судить о событии, событийствовать миру во всех смыслах, включая смыслы политические. В тоталитарных обществах эта свобода изъята у индивида и перенесена на высокий уровень государственных решений. Можно быть только вместе и только в колее, заданной государственной пропагандой, любой отход от линии, которая задана властью, наказуем. Свободная мысль на индивидуальном уровне, на том уровне, где живет Уинстон Смит, главный герой романа

1 Статья Р.Р. Вахитова «Правильно ли мы понимаем “1984”», опубликованная в этом номере журнала на стр. 151-162. 
«1984», - это тяжкое преступление, за которое неминуемо следует жестокая расплата. На уровне тоталитарного государства свобода манипулирования понятиями становится важнейшей характеристикой процесса управления: «Особенность тоталитарного государства та, что, контролируя мысль, оно не фиксирует ее на чем-то одном. Выдвигаются догмы, не подлежащие обсуждению, однако изменяемые со дня на день. Догмы нужны, поскольку нужно абсолютное повиновение подданных. Однако невозможно обойтись без коррективов, диктуемых потребностями политики власть предержащих. Объявив себя непогрешимым, тоталитарное государство вместе с тем отбрасывает само понятие объективной истины. Вот очевидный, самый простой пример: до сентября 1939 г. каждому немцу вменялось в обязанность испытывать к русскому большевизму отвращение и ужас, после сентября 1939 г. - восторг и страстное сочувствие. Если между Россией и Германией начнется война, а это весьма вероятно в ближайшие несколько лет, с неизбежностью вновь произойдет крутая перемена. Чувства немца, его любовь, его ненависть при необходимости должны моментально обращаться в свою противоположность» [Оруэлл 2015, с. 133].

Контроль над мыслью - это в первую очередь контроль над языком, над тем, как люди говорят, какими средствами описания они владеют. Язык, как свидетельствует современная наука, - это таинственная область, в которой сходятся вместе логика и практический смысл. Класс бюрократии, похищающий государство, овладевает искусством подмены понятий и оценочных модусов. И вот уже руководитель, весь смысл деятельности которого заключается в том, чтобы выжать из предприятия максимум прибыли, удерживая заработные платы рабочих на минимальных значениях, именуется «эффективным менеджером». Способ производства, базирующийся на добыче и экспорте необработанного сырья, преобразуется нехитрыми словесными манипуляциями в «экономику впечатлений», предел мечтаний для обывателя. Усыхание сферы социальной защиты - здравоохранения или образования - становится «оптимизацией», приведением соответствующей области к ее оптимальному, якобы необходимому состоянию. Новояз, язык манипуляции (и здесь Дж. Оруэлл опередил свое время), расцветает в эпоху постправды и фейков, передергиваний и обмана во имя обретения и продления властных полномочий, во имя удержания небольшой группой власть имущих ключевых ресурсов жизнеобеспечения под контролем. Семантические манипуляции имеют ограниченную применимость в том случае, если подчиняются законам логики, но в тоталитарных государствах правила формальной логики подвержены замене диалектической эквилибристикой, рождая двоемыслие: мир - это война, свобода это рабство, любовь - это ненависть.

О любви в условиях, когда в переулках и магистралях общественный мысли расставлены патрули, сказано отдельно: любовь бесконтрольная возможна лишь в том случае, если она сфокусирована на фигуре вождя. В остальном любовь находится в узких рамках дозволенного, и здесь Дж. Оруэлл следует сложившейся традиции - роману Евгения Замятина «Мы» и роману Олдоса Хаксли «Смелый новый мир». В этих произведениях любовная повестка дня перехватывается властью и ставится себе на службу, но природа любви такова, что удержание ее в рамках невозможно. У Е. Замятина любовь расшатывает основания рационального, тоталитарного устройства, у Дж. Оруэлла она становится вызовом тоталитарной диктатуре, побуждая героя встать на путь нарушения ее запретов и предписаний. 
О тонких взаимодействиях личных переживаний, эмоциональных привязанностей и властной воли в эпоху революционной диктатуры размышлял не только Дж. Оруэлл, но и революционеры, осознавшие пределы преобразовательной политики. Лев Троцкий, поняв, что революция зашла в тупик и что теория оказалась мертва перед жизнью, увлекся психоанализом, видя в нем возможность «вычистить колодцы» индивидуального сознания так, чтобы сама мысль об обладании чем бы то ни было исключалась из области человеческих отношений. Александр Эткинд, рассказавший об этом эпизоде из жизни Л. Троцкого, увидел в этом его увлечении прежде всего интертекстуальность, пересечение разных идей и разных интеллектуальных традиций, попытку рассудочно решить проблему микро-макро, извечную для общественной науки и в данном случае политической практики [Эткинд 2001]. Попытку, которая для Л. Троцкого и его семьи закончилась трагически: тайны бессознательно обернулись против революционера, против его утопических идей тотального контроля.

В конце романа главный герой «1984» подавлен, сломлен, лишен надежды и только по итогу пережитого готов полюбить Большого Брата, но конец личной истории не означает завершение истории как таковой. В настоящей истории Большой Брат вынужден отступить, уйти, закрыться от внешней силы, переосмыслив стратегию господства, способы надзора, чтобы в следующий раз, по мере того как станут массовыми новые технологии, вернуться к манипуляции массой, и в этот раз более эффективной.

Так о чем же писал свои книги Дж. Оруэлл? Что хотел он сказать своим современникам и будущим поколениям? Ричард Рис, бывший редактор журнала The Adelphi, в котором Дж. Оруэлл часто публиковал свои эссе, написал биографию писателя под названием «Джордж Оруэлл: беглец из лагеря победителей» [Rees 1962]. Рис полагал, что для Дж. Оруэлла было характерно острое переживание несправедливости во всех ее формах, желание сыграть на стороне справедливости, восстанавливая баланс общественных сил. Для того, полагал он, ему достаточно бросить свой вес на ту чашу весов, которая сегодня легче. Именно поэтому, считал Р. Рис, Дж. Оруэлл оказался на стороне тех, кого считал обездоленными, the underdog, фабричных рабочих, безработных, мелких ремесленников, пострадавших в результате Великой депрессии. Именно поэтому он вступил в Объединенную рабочую марксистскую партию (POUM), преследуемую сильными партиями, получающими поддержку Коминтерна. Джордж Оруэлл, как отмечают его биографы, не был силен в философии или политической теории, и он точно не имел подробных развернутых представлений о том, что происходит в тех странах, в которых не бывал. Так в чем же сила его произведений? Почему его числят по-прежнему, спустя многие десятилетия, важнейшим писателем ХХ столетия? Возможно, все дело в том, что он действительно умел заглядывать в будущее, ставить проблемы раньше, чем они появились, и тем самым предупреждать о тех опасностях, которые грозят обществам по мере того, как развиваются технологии, как мир индивидуальный становится все более проницаемым, просматриваемым со всех сторон электронным Паноптиконом. Но, возможно, он обязан своей популярностью и тому, что в эпоху великих противостояний сумел, как немногие, сохранить свободу говорить то, что думает, быть самим собой тогда, когда это было особенно непросто. 


\title{
Литература
}

Оруэлл Дж. (2003) Памяти Каталонии. М.: АСТ-Ермак.

Оруэлл Дж. (2012) Дни в Бирме. М.: Астрель Неоклассик.

Оруэлл Дж. (2015) Литература и тоталитаризм // Оруэлл Дж. Скотный Двор. Эссе. М.: АСТ.

Оруэлл Дж. (2016) 1984. М.: АСТ.

Оруэлл Дж. (2017) Скотный Двор. Эссе. М.: АСТ.

Оруэлл Дж. (2018) Фунты лиха в Париже и Лондоне. Дорога на Уиган-Пирс. М.: АСТ.

Эткинд А. (2001) Толкование путешествий: Америка и Россия в интертекстах и травелогах. М.: НЛО.

Ingle S. (2005) The Social and Political thought of George Orwell, London: Routledge.

Nickols J. (2007) Alexander Kojeve: Wisdom at the End of History, New York: Rowman and Littlefield Publishers.

Podhoretz N. (1983) If Orwell Were Alive Today // Harper's, January 1983, pp. 63-82.

Rees R. (1962) George Orwell: Fugitive from the Camp of Victory, South Illinois University.

\section{Orwell: An Honest Word in the Times of Ideological Conflicts}

\section{CHERNYSH*}

\begin{abstract}
*Mikhail Chernysh - Corresponding Member of the Russian Academy of Sciences, DSc in Sociology, Deputy Director, Institute of Sociology, Russian Academy of Sciences. Address: bld. 5, 24/35, Krzhizhanovskogo St., Moscow, 117218, Russian Federation. E-mail: che@isras.ru

Citation: Chernysh M. (2021) Orwell: An Honest Word in the Times of Ideological Conflicts. Mir Rossii, vol. 30, no 1, pp. 163-172 (in Russian). DOI: $10.17323 / 1811-038 X-2021-30-1-163-172$
\end{abstract}

\begin{abstract}
In Russia, Orwell is often regarded as a harsh critic of the totalitarian regime and the author of two famous novels "1984" and "Animal Farm". However, the legacy of Orwell cannot be reduced to these important literary works. Orwell was an advocate of socialism, came out as an opponent of the British colonial policies, fought against fascism in Spain and was seriously wounded there. His anti-totalitarian stance was not tied to any particular geographical location. He viewed totalitarian practices as the development of inequality and the evolution of domination inherent in capitalist society. Orwell sought to preserve the right to have an independent voice and to support the cause of justice.
\end{abstract}

Keywords: Orwell, capitalism, colonialism, inequality, totalitarianism, domination, justice 


\section{References}

Etkind A. (2001) Tolkovanie Puteshestvii: America and Rossiya v intertekstakh i travelogakh [Interpreting Travels: America and Russia in Intertexts and Travelogs], Moscow: NLO.

Ingle S. (2005) The Social and Political thought of George Orwell, London: Routledge.

Nickols J. (2007) Alexander Kojeve: Wisdom at the End of History, New York: Rowman and Littlefield Publishers.

Orwell G. (2003) Pamyati Katalonii [Homage to Katalonia], Moscow: AST-ERMAK.

Orwell G. (2012) Dni v Birme [Days in Burma], Moscow: Astrel Neoklassik.

Orwell G. (2015) Literatura i totalitarism [Literature and Totalitarianism]. Orwell G. Skotnyi Dvor. Esse [Animal Farm. Essays], Moscow: AST.

Orwell G. (2016) 1984, Moscow: AST.

Orwell G. (2017) Skotnyi Dvor. Esse [Animal Farm. Essays], Moscow: AST.

Orwell G. (2018) Funti Likha v Parizhe $i$ Londone. Doroga na Uigan Pirs [Down and Out in Paris and London. The Road to Wigan Pier], Moscow: AST.

Podhoretz N. (1983) If Orwell Were Alive Today. Harper's, January 1983, pp. 63-82.

Rees R. (1962) George Orwell: Fugitive from the Camp of Victory, South Illinois University. 